\title{
Unanswered questions for implementation of the Sustainable Groundwater Management Act
}

Michael Kiparsky, Director, Wheeler Water Institute, Center for Law, Energy \& the Environment, UC Berkeley School of Law

C alifornia is grappling with the implications of the Sustainable Groundwater Management Act (SGMA), a visionary and potentially revolutionary law that could profoundly change the way water is managed in the state.

The nature of the revolution, however, is not yet clear. Whether and how SGMA achieves its goals hinges on open questions about its implementation.

Groundwater accounts for between one-third and two-thirds of California's water use in a given year and serves as a lifeline when surface water runs low during drought. In part because of California's historical lack of groundwater use regulation, this crucial resource is threatened. In some areas, declining groundwater levels have caused the land surface to subside at a rate of more than one inch per month, damaging roads, canals and pipelines. Falling water tables are driving a well-drilling race that threatens farms, communities and ecosystems.

To address the problem of chronic groundwater overdraft, SGMA, adopted in 2014, declares a state policy of managing groundwater sustainably, with sustainability defined as avoiding six specific undesirable results. These are "significant and
A rig drills a new well in Merced County. In the foreground is a pressure relief structure for subsurface water pipes. unreasonable" (1) lowering of groundwater levels, (2) reduction in groundwater storage, (3) seawater intrusion, (4) water quality degradation, (5) land subsidence and (6) impacts on beneficial uses of interconnected surface waters.

In concept, this forward-thinking framing aligns the requirements of the law with the impacts of unsustainable groundwater use and the actions needed to address those impacts.

To accomplish these objectives, SGMA relies primarily on local control, with an enforcement backstop provided by the State Water Resources Control Board. New local entities called groundwater sustainability agencies (GSAs) will do the bulk of the work of implementing SGMA by developing, implementing and updating groundwater sustainability plans (GSPs). A GSP provides the template for achieving sustainable groundwater management in a GSA's jurisdiction within 20 years. GSAs must be formed by 2017 and GSPs completed by 2020 or 2022.

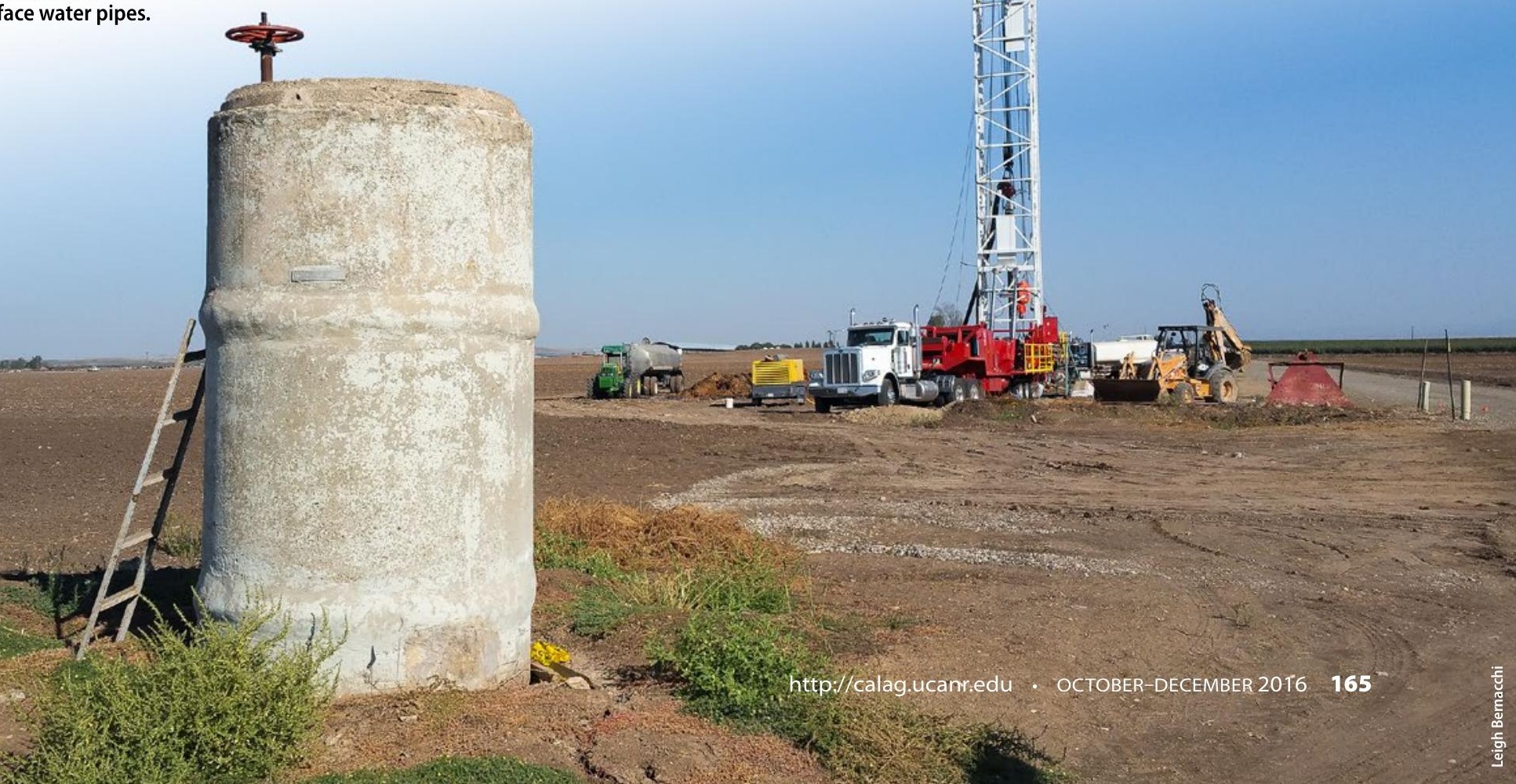




\section{A groundwater} pump at the Russell Ranch Sustainable Agriculture Facility near UC Davis.
Given this framework, much about how SGMA will be implemented has yet to be determined. In the next few years, decisions about these details will be made that will have major implications for whether SGMA succeeds in achieving groundwater sustainability.

We may not know for decades whether and where sustainability has been achieved. Among many questions about SGMA's implementation, the following seven may help us consider important unknowns about California's water future under SGMA.

\section{Governance}

How will GSAs be structured? Decisions about governance and institutional design are being made now, so immediate attention to this question is imperative. In a recent report (Kiparsky et al. 2016), my collaborators and I developed nine criteria for fair and effective GSAs; three stand out at this juncture.

Scale is a crucial element. In most cases, the jurisdiction of a management agency would ideally match the scale of the resource being managed. But efforts to match jurisdictional scale to groundwater basins appear to be rare in the 127 groundwater basins affected by SGMA. Many basin maps could end up looking more like GSA patchwork quilts. In this experiment, transaction costs or ultimately even management effectiveness may be at stake.

Human capacity is also essential for GSAs. Funding, technical ability, legal expertise and management skills are essential for GSAs to be capable of handling the difficult tasks ahead of them. Two examples: To understand basin conditions and develop robust sustainability indicators and plans, managers will need in-house technical expertise, regardless of support lent by the state or consultants. Further, substantial administrative, policy and legal expertise will be required to develop funding for GSA activities through appropriate groundwater extraction fees, particularly given constitutional provisions such as Proposition 218 that circumscribe public agencies' authority to collect funds.

Finally, broad and meaningful public participation and representation are essential to the development of effective programs that account for the range of interests affected by a GSA's actions. In many areas, ensuring effective participation of stakeholder groups that would otherwise lack the resources to engage may require active support by the GSA, the state or third parties.

\section{Translating sustainability goals into practice}

How will the sustainability goals specified by SGMA translate, where necessary, into reductions in net groundwater extraction?

Broadly speaking, there are three approaches to changing the water balance in a groundwater basin:

- Groundwater users can reduce groundwater use;

- Groundwater users can replace some groundwater use with alternative supplies, such as imported surface water or recycled water; or

- Groundwater users or managers can recharge aquifer systems with stormwater, peak flood flows, recycled water or imported surface water.

Combinations of these strategies will vary, influenced by basin conditions, basin politics and other local factors.

In many areas, limitations on groundwater pumping will be required to avoid undesirable results. 


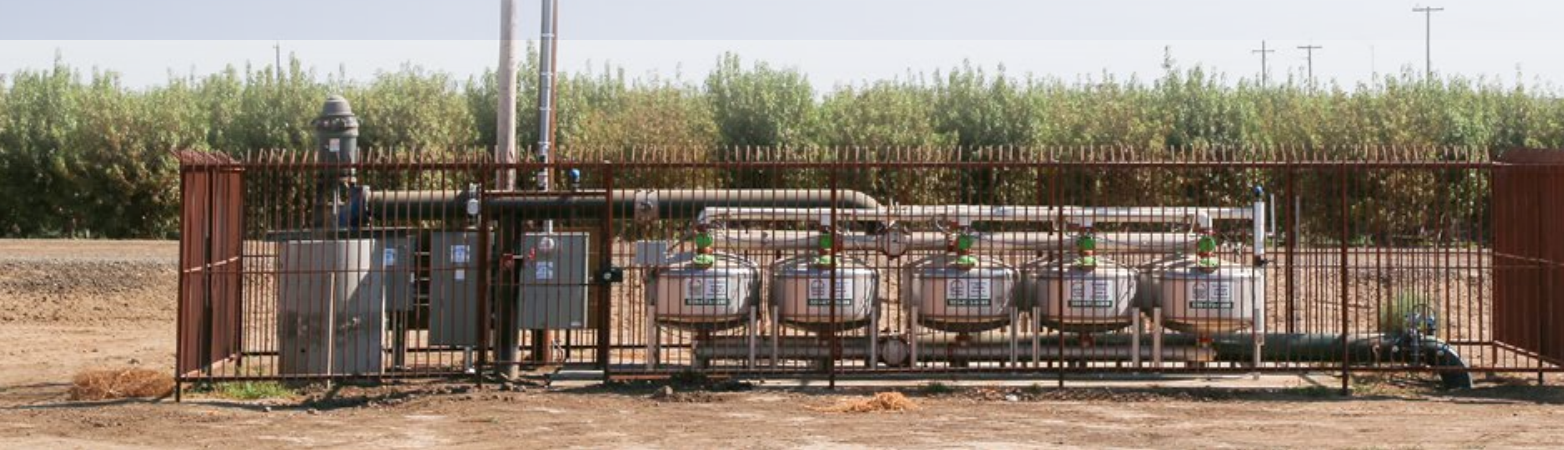

Determining extraction caps and allocating them among competing interests will be both technically challenging and controversial. SGMA does not specify how much groundwater may be withdrawn in a given basin; rather, sustainable yield is defined in terms of avoidance of undesirable results, which are locally specific and will be defined in large part by GSAs. Politically, we can expect resistance from groundwater users accustomed to unfettered access to the resource. Defining effective and efficient pathways through technical controversies, stakeholder negotiations, public participation processes, financing issues and other inevitable challenges will test the skill of all involved.

\section{Groundwater-surface water interactions}

How will SGMA influence surface water, and vice versa? One of the most promising, and potentially most fraught, aspects of SGMA is that it calls out the interactions between groundwater and surface water. Although hydrologists and water managers have long recognized that surface flows and groundwater conditions are tightly linked, California water law reinforces artificial distinctions between the two.

Sustainable management under SGMA will include consideration of impacts on surface water (the sixth "undesirable result", above) in two ways. The first is avoiding significant and unreasonable harm to surface water rights holders - implying a need to maintain groundwater levels sufficient to support interconnected rivers and streams. The second is avoiding significant and unreasonable harm to groundwater-dependent ecosystems - rivers and streams, but also wetlands and springs.

The challenge for GSAs will be making decisions that are technically sound and ecologically meaningful, while balancing the tensions these choices may create among different users and uses of groundwater and surface water.

\section{The role of markets}

How can, and how should, market mechanisms be used as part of SGMA implementation? Where SGMA compliance requires reduced pumping, it will affect the economics of groundwater. Many water agencies already augment water supplies by buying water from within or outside their basins. SGMA explicitly authorizes groundwater transfers as one potential tool for achieving sustainability, but does not provide specific guidance about such transfers or the markets they imply.

Markets can be excellent tools for improving efficiency in that they can help redistribute water to higher-value uses. However, poorly designed markets also can create externalities (impacts to third parties or the environment). Further, poorly designed markets can exacerbate inequity, potentially raising legal concerns.

Whether effective and fair groundwater markets develop will depend on GSAs' ability to design and enforce appropriate market rules, as well as on unanswered questions about how groundwater rights law influences the development of extraction allocations and their transferability.

\section{The role of data}

What data will be collected and shared by GSAs? SGMA empowers, but does not require, GSAs to collect groundwater extraction data from individual wells, and it requires only aggregated extraction data to be shared and reported to the state. Even if GSAs conduct appropriate monitoring and modeling, regulators and stakeholders may have to view the groundwater system within each GSA boundary as a black box, obscuring coordination, public participation and effective oversight.

SGMA promises unprecedented collection of data in California. But even so, data does not lead automatically to better management. Some GSAs will choose to collect and share copious data. Others may not. GSAs and the state should ensure that sufficient data are collected, made public, and used to aid planning, management and oversight. Creating a common data framework that is at once flexible, transparent, and effective will be an essential, and non-trivial, first step.

\section{The role of the State Water Board}

When and how will the State Water Resources Control Board (Board) enter the SGMA process? SGMA makes local GSAs primarily responsible for sustainable groundwater management. Recognizing that some
A groundwater pumping system in Merced County. 
GSAs might not achieve, or even robustly pursue, that goal, SGMA gives the Board a vital "backstop" enforcement role.

This is a whole new area for the Board, and we don't know how it will approach the role in practice.

Some of the Board's intervention points are clear now: for example, there are clear deadlines for GSAs to be in place in medium- and high-priority basins. Others are less so: SGMA does not specify exactly under what conditions intervention based on GSP inadequacy will be warranted, for instance. Strong engagement by the Board will be needed.

\section{7. "Significant and unreasonable"}

What does "significant and unreasonable" actually mean? The core of SGMA is preventing undesirable impacts, but these impacts are not unambiguously defined or quantified in the law or its attendant new regulations. Rather, GSAs themselves will define - implicitly or explicitly — what they think significant and unreasonable impacts are, based on the thresholds and measurable objectives they choose to adopt.

GSAs will need to navigate these and other value-based choices in defensible ways. Ultimately, unresolved conflicts could lead to litigation. Then, the courts may play a role in clarifying what impacts meet the threshold of "significant and unreasonable." Where this happens, it may represent a departure from the principle of local control that is so central to SGMA.

\section{The role of innovation}

This extensive list of questions is not meant to suggest that SGMA is unlikely to succeed. The questions are not unanswerable, much effort is already underway to address them, and there are good reasons for optimism.

SGMA incentivizes innovation, simply by regulating groundwater for the first time, and by doing so in a flexible way. Our work on innovation in the water sector suggests that progress requires more than just new technology (Kiparsky et al. 2013). It also requires surmounting institutional barriers to bring new ideas into broader practice.

Here are two emerging innovations that SGMA is already helping to catalyze.

The first is tapping the potential for groundwater recharge on farmlands using winter storm flows. In the same way that Apple assembled existing microprocessor, battery and display technologies and developed the iPhone, a number of researchers, including Helen Dahlke (UC Davis), Phil Bachand (Bachand \& Associates) and others, are combining underutilized resources - winter flood flows, water conveyance infrastructure and offseason farmland - together to create something new (Bachand et al. 2013; Bachand et al. 2016; Harter and Dahlke 2014; O'Geen et al. 2015).

A second emerging concept is recharge net metering - an example of an innovation that builds on an idea from another sector. Photovoltaic net metering, widely used in the electricity sector, made it economically feasible for me to install solar panels on the roof of my house by allowing me to sell excess power the panels generate when the sun is shining and to buy electricity from the utility to use in the evening. The difference determines my annual electricity bill. In the Pajaro Valley, a partnership including Andy Fisher (UC Santa Cruz), the Resource Conservation District-Santa Cruz County and the Pajaro Valley Water Management Agency is working to develop an analogous scheme for aquifer recharge (PVWMA 2015). Landowners who invest in projects to infiltrate stormwater receive a credit against the fees they pay when pumping groundwater. What's exciting about this scheme is its potential to align the interests of landowners with the broader health of the aquifer and to provide another tool for addressing challenges in a common resource.

To be sure, a host of barriers remain to the diffusion of these innovations, including water quality, logistical, economic, legal and financing challenges. And neither is a magic bullet for groundwater management. But both illustrate how SGMA already is both forcing and enabling creative thinking.

This type of creative thinking will be critical for California to implement SGMA successfully and transform from a national laggard in groundwater management into an international leader. Thankfully, the state is rising to the occasion. State agencies are meeting milestones under extraordinary time pressure, and NGO, academic, and industry groups are producing timely analyses to point out problems and identify solutions.

As indicated here, the law presents significant challenges for both public and private sectors and requires tough decisions to be made under considerable uncertainty. Whether California can muster the leadership, scientific and engineering innovation, and administrative skill to meet these challenges will ultimately determine how revolutionary SGMA actually is. CA

This text is adapted from remarks in a keynote address (video: bit.ly/2bw63HO) to the 2nd International Groundwater and Agriculture Conference in June 2016 (aggroundwater.org). Holly Doremus, Nell Green Nylen and Thomas Harter provided useful feedback. This work is a product of the UC Water Security and Sustainability Research Initiative (ucwater.org), supported by the UC Office of the President.

\section{References}

Bachand PAM, Roy SB, Choperena J, et al. 2013. Implications of using on-farm flood flow capture to recharge groundwater and mitigate flood risks along the Kings River, CA. Environ Sci Technol 48(23):13601-9. doi:10.1021/es501115c.

Bachand PAM, Roy SB, Stern N, et al. 2016. On-farm flood capture could reduce groundwater overdraft in Kings River Basin. Calif Agr 70(4):200-207. doi:10.3733/ ca.2016a0018.

Harter T, Dahlke HE. 2014. Out of sight but not out of mind: California refocuses on groundwater. Calif Agr 68(3):54-5. doi:10.3733/ca.v068n03p54

Kiparsky M, Owen D, Nylen NG, et al. 2016. Designing effective groundwater sustainability agencies: Criteria for evaluation of local governance options. UC Berkeley Center for Law, Energy \& the Environment. http://bit.ly/2236VHC.

Kiparsky M, Sedlak DL, Thompson Jr BH, Truffer B. 2013. The innovation deficit in urban water: the need for an integrated perspective on institutions, organizations, and technology. Environ Eng Sci 30(8):395-408. doi:10.1089/ees.2012.0427.

O'Geen AT, Saal MB, Dahlke HE, et al. 2015. A soil survey decision support tool for groundwater banking in agricultural landscapes. Calif Agr 69(2):75-84. doi:10.3733/ ca.v069n02p75

[PVWM] Pajaro Valley Water Management Agency. 2016. News release: PVWater launches landmark groundwater rebate program. http://bit.ly/2bb1qHP. 